\title{
Characterizing opioid use in a US population with migraine
}

Results from the CaMEO study

Richard B. Lipton, MD, Dawn C. Buse, PhD, Benjamin W. Friedman, MD, Lisa Feder, PhD, Aubrey Manack Adams, PhD, Kristina M. Fanning, PhD, Michael L. Reed, PhD, and Todd J. Schwedt, MD

Neurology ${ }^{\circledR}$ 2020;95:e457-e468. doi:10.1212/WNL.0000000000009324

\section{Abstract}

\section{Objective}

To determine the prevalence of and risk factors associated with opioid use in the treatment of migraine, we examined demographics and clinical characteristics of 867 individuals who reported using opioids for the treatment of migraine.

\section{Methods}

We analyzed data from the CaMEO study (Chronic Migraine Epidemiology and Outcomes), a cross-sectional, longitudinal, Internet study, to compare sociodemographics, clinical characteristics, and migraine burden/disability of opioid users vs nonusers. Covariates were entered as categorical or continuous variables. Factors associated with opioid use were identified using nested, multivariable binary logistic regression models.

\section{Results}

Of 2,388 respondents with migraine using prescription medications for acute treatment, $36.3 \%$ reported that they currently used or kept on hand opioid medications to treat headaches. Current opioid users had significantly more comorbidities, greater headache-related burden, and poorer quality of life than nonusers. Regression models revealed factors significantly associated with opioid use, including male sex, body mass index, allodynia, increasing monthly headache frequency, Total Pain Index score (excluding head, face, neck/shoulder), anxiety, depression, $\geq 1$ cardiovascular comorbidity, and emergency department/urgent care use for headache in the past 6 months. Self-reported physician-diagnosed migraine/chronic migraine was associated with significantly decreased likelihood of opioid use.

\section{Conclusions}

Of respondents who were using acute prescription medications for migraine, more than onethird used or kept opioids on hand, contrary to guidance. This analysis could not distinguish risk factors from consequences of opioid use; thus further research is needed to guide the development of strategies for reducing the inappropriate use of opioids in migraine.

\author{
Correspondence \\ Dr. Lipton \\ Richard.Lipton@ \\ einsteinmed.org
}

MORE ONLINE

- CME Course

NPub.org/cmelist

From the Department of Neurology (R.B.L., D.C.B., B.W.F.), Albert Einstein College of Medicine, Bronx, NY; Peloton Advantage, LLC, an OPEN Health Company (L.F.), Parsippany, NJ; Global Medical Affairs (A.M.A.), Allergan plc, Irvine, CA; Vedanta Research (K.M.F., M.L.R.), Chapel Hill, NC; and Neurology Research (T.J.S.), Mayo Clinic, Phoenix, AZ.

Go to Neurology.org/N for full disclosures. Funding information and disclosures deemed relevant by the authors, if any, are provided at the end of the article. 


\section{Glossary}

AMPP = American Migraine Prevalence and Prevention; BMI = body mass index; CaMEO = Chronic Migraine Epidemiology and Outcomes; $\mathbf{C I}=$ confidence interval; $\mathbf{C V}=$ cardiovascular; $\mathbf{E D}=$ emergency department; GAD-7 = 7-item Generalized Anxiety Disorder scale; HCP = health care professional; ICHD-3 = International Classification of Headache Disorders, 3rd edition; MIDAS = Migraine Disability Assessment; $\mathbf{M O H}=$ medication overuse headache; $\mathbf{M S Q}=$ Migraine-Specific Quality of Life Questionnaire; MSSS = Migraine Symptom Severity Score; NSAID = nonsteroidal anti-inflammatory drug; OR = odds ratio; PHQ-9 = 9-item depression module of the Patient Health Questionnaire scale; TPI = Total Pain Index; UC = urgent care.

Migraine, a highly prevalent, chronic neurologic disease, typically manifests with episodic attacks of pain associated with other incapacitating symptoms, such as nausea, photophobia, phonophobia, and allodynia. ${ }^{1,2}$ The second-highest specific cause of disability worldwide, ${ }^{3}$ migraine produces substantial individual, familial, economic, and societal burdens. ${ }^{4-6}$ Management of migraine includes acute and preventive medication, as well as nonpharmacologic approaches. The goals of acute treatment include rapid resolution of pain and associated symptoms without recurrence, side effects, and the need for backup or rescue medications. ${ }^{7}$ Practice guidelines do not recommend opioids for treating migraine except under limited circumstances. However, a substantial proportion of individuals use opioids for acute treatment of migraine..$^{7-12}$ In the American Migraine Prevalence and Prevention (AMPP) study, approximately $30 \%$ of community-residing respondents reported opioid use for migraine. ${ }^{9}$ In the emergency department (ED), $59 \%$ of visits for migraine involved opioid administration or prescription. ${ }^{10}$ Despite the potential for short-term benefits, opioids are associated with only modest initial efficacy, increased risk for migraine chronification, ${ }^{13-17}$ and potential for misuse, abuse, and dependence. ${ }^{9,18}$

Factors associated with opioid use for migraine require additional exploration as a step toward preventing the negative consequences of this common pattern of treatment. This analysis of the Chronic Migraine Epidemiology and Outcomes (CaMEO) study explored demographic and clinical characteristics associated with opioid use for migraine.

\section{Methods}

\section{Study design}

The CaMEO study characterized the course of migraine over 1 year in a broad cohort of respondents with migraine representative of the US population. Details of the study design have been published previously. ${ }^{19}$ Briefly, CaMEO is a crosssectional and longitudinal Internet study with screening, recruitment, and assessment phases. CaMEO was designed to characterize the clinical course of migraine, family burden, barriers to care, endophenotypes, and comorbidities among respondents with chronic and episodic migraine using both cross-sectional and longitudinal study modules. This analysis evaluated data from the comorbidities and core modules. The modules collected data from respondents who passed the screener and were assessed every 3 months on a broad set of features and conditions, including migraine characteristics, allergies and respiratory disorders, cardiovascular disease, chronic pain, chronic fatigue, sleep disorders, autonomic disorders, psychiatric disorders, gastrointestinal disorders, and overactive bladder.

From September to October 2012, screening and recruitment of study respondents occurred from an Internet research panel (Research Now, Plano, TX) with 2.4 million active US members, with cross-sectional and longitudinal CaMEO study modules administered from September 2012 to November 2013 and longitudinal assessments occurring at 3-month intervals (3, 6, 9, and 12 months after the baseline assessment). The CaMEO study was approved by the Albert Einstein College of Medicine Institutional Review Board (12-04-177E). All study authors had full access to all data.

\section{Standard protocol approvals, registrations, and patient consents}

Data included in this analysis were from the CaMEO study (ClinicalTrials.gov identifier: NCT01648530). The institutional review board of the Albert Einstein College of Medicine approved the CaMEO study and waived written informed consent for study volunteers, who had the right to accept or refuse participation in the survey.

\section{Study respondents}

This study used quota sampling with the aim of recruiting a demographically representative sample of the United States based on age, sex, and income. ${ }^{19}$ Eligible respondents were at least 18 years of age, agreed to participate, completed initial surveys in a reasonable time (at least 10 minutes), provided data on headache frequency, reported consistent age and sex throughout the survey, and met modified International Classification of Headache Disorders, 3rd edition (ICHD-3) symptom criteria for migraine using the validated American Migraine Study/AMPP study migraine screener. ${ }^{1,20}$ Classification into chronic or episodic migraine was determined by using modified Silberstein-Lipton criteria (headache frequency of at least 15 days [chronic migraine] or fewer than 15 days [episodic migraine] per month over the preceding 3 months). ${ }^{1}$

\section{Variables: sociodemographics, clinical characteristics, and other factors associated with opioid use}

This analysis compared sociodemographics, clinical characteristics, and migraine-related disability of self-reported 
opioid users and nonusers who met criteria for migraine. Sociodemographic characteristics included age, sex, employment, education, income, and body mass index (BMI). Headache characteristics included monthly headache days, Migraine Disability Assessment (MIDAS; score based on 5 disability questions in 3 areas, assessed over the preceding 3 months), ${ }^{21}$ and Migraine Symptom Severity Score (MSSS), a composite index based on the frequency of 7 primary migraine features (unilateral pain, pulsatile pain, moderate or severe pain intensity, routine activities worsening pain, nausea, photophobia, and phonophobia). Responses ranged from 1 to 4 , with the overall sum score ranging from 7 to 28 . The presence of cutaneous allodynia was determined using the 12-item Allodynia Symptom Checklist, in which scores of at least 3 indicate the presence of allodynia. ${ }^{22}$ Noncephalic pain data were collected using the validated Total Pain Index (TPI). The TPI assesses pain frequency and intensity over the preceding 3 months in 8 specified body regions (head, face, neck or shoulders, back, arms or hands, legs or feet, chest, and abdomen or pelvis). Pain noted at "any other location" was recorded and attributed to its specific respective body part. It replaced the pain value for a given location only if worse than the original score. For each location, respondents rated their pain from 0 (no pain) to 10 (worst pain imaginable). Respondents also rated pain frequency on a scale from 0 (none of the time) to 4 (all of the time). These ratings were recoded to $0=0 \%$ of the time, $1=35 \%, 3=75 \%$, and $4=100 \%$ of the time to provide an estimate of the approximate amount of time represented by each response. The TPI was derived by multiplying the pain frequency percentage for each body location by its pain rating. The score for each location can range from 0 to 10 , with total scores ranging from 0 to 80 . This analysis considered head, face, and neck or shoulder pain to be cephalic pain, removing them from TPI scoring, leaving 5 body locations and a possible score range of $0-50$.

Health care variables included physician diagnosis of migraine or chronic migraine and use of an ED or urgent care (UC) facility in the preceding 6 months for headache. Other respondent characteristics included psychiatric comorbidities, including anxiety and depression, presence of at least 1 cardiovascular (CV) comorbidity (heart disease or angina, heart attack, irregular heart rhythms, any heart valve disease or abnormality, hypertension, stroke, and TIA), and Migraine-Specific Quality of Life Questionnaire (MSQ) consisting of 3 domains, which included role function: preventive, role function: restrictive, and emotional, scored on a scale ranging from 0 to 100 , with higher scores indicating better quality of life. Depression was assessed using the 9-item depression module of the Patient Health Questionnaire scale (PHQ-9), with scores ranging from 0 to 27 , as each of the 9 items can be scored from 0 (not at all) to 3 (nearly every day). ${ }^{23}$ Scores greater than 10 were categorized as moderate to severe depression. Anxiety was assessed using the 7-item Generalized Anxiety Disorder scale (GAD7 ), with scores ranging from 0 to 21 , as each of the 7 items is scored from 0 to $3 .^{24}$ Scores of at least 10 were categorized as positive for anxiety. Respondents reporting current use of medications for the acute treatment of migraine attacks indicated which medications they were taking, or had available to use, by referring to a precoded list and answering the question "Which of these medications (if any) are you currently using (or typically keep on hand) to treat your headaches when you have them?" The precoded list included both generic and brand names of triptans, opioids, barbiturates, ergotamines, and nonsteroidal anti-inflammatory drugs (NSAIDs).

The present analysis defined current opioid users as individuals who self-reported current use of an opioid or had opioid medicine on hand to treat headache. Opioid use indicating risk for medication overuse headache $(\mathrm{MOH})$ was defined as opioid use on at least 10 days each month to best align to the ICHD-3 criteria. ${ }^{1}$ Opioid users confirmed use of at least 1 of the following prescription opioid medications: acetaminophen/codeine, acetaminophen/hydrocodone, acetaminophen/oxycodone, acetaminophen/oxycodone hydrochloride, hydrocodone, meperidine, morphine, oxycodone, oxycodone hydrochloride, propoxyphene, propoxyphene/acetaminophen, tramadol, tramadol/acetaminophen, and hydrocodone/ibuprofen.

\section{Statistical analysis}

A cross-sectional analysis compared the sociodemographics, clinical characteristics, and migraine-related disability of selfreported opioid users and nonusers who met criteria for migraine. With the exception of age and BMI, sociodemographic covariates were coded as categorical variables. For clinical characteristics and migraine-related disability, mean monthly headache frequency, MSSS, and MSQ scores were coded as continuous variables. Factors classed as other clinical characteristics were coded as categorical variables. Between-group (opioid users vs nonusers) differences in continuous variables were assessed using a 2-tailed $t$ test. The $\chi^{2}$ test was used for testing between-group differences in categorical variables. For all tests, $\alpha$ was set at 0.05 .

A series of nested multivariable binary logistic regression models, in which opioid use vs nonuse was the dependent variable, assessed factors associated with opioid use. Covariates were entered in sequential blocks, starting with sociodemographic variables, followed by headache and respondent characteristics, and health care variables. The final model was adjusted for the presence of at least 1 cardiovascular comorbidity. Odds ratios (ORs) (95\% confidence interval $[\mathrm{CIs}]$ ) were calculated for each variable. After each block was entered, nonsignificant variables were trimmed from the model.

\section{Data availability}

Data reported in this manuscript are available within the article. Additional data from the CaMEO study (ClinicalTrials. gov Identifier: NCT01648530) may be requested at allerganclinicaltrials.com/en/patient-data. 


\section{Results}

\section{Analysis population and sociodemographics}

During the screening phase, the CaMEO study invited a total of 489,537 respondents from the 2.4 million active US members listed in the Research Now database (figure 1). ${ }^{19} \mathrm{~A}$ total of 16,789 respondents qualified for inclusion in the CaMEO study during the recruitment phase. From this group, 12,810 respondents completed the comorbidities module. ${ }^{19}$ Of these, 10,431 reliably reported the use of 1 or more acute medications for migraine and 2,388 (22.9\%) were current users of prescription medication for the acute treatment of migraine. Among people with migraine treated with acute prescription medications, 867 (36.3\%) reported opioid use, and $1,521(63.7 \%)$ did not.

The 2,388 respondents categorized as current users of prescription medication for acute treatment of migraine attacks had a mean age of approximately 46 years. Most respondents were women, white, and insured (table 1). Nearly two-thirds of the respondents were employed, and $99 \%$ had a source of household income (based on the total income from all people living in a particular household); among these, more than 60\% had an annual income of $\$ 50,000$ or more. More than half were married, and nearly half of the respondents had a college degree. Respondents who reported opioid use were more likely than opioid nonusers to be male, have a higher BMI, and have lower income. They were less likely to be employed and have a 4-year college degree.

\section{Headache characteristics and health care variables}

Opioid users had significantly more monthly headache days than nonusers (table 2). They also reported significantly more medication use. Nearly $80 \%$ of all current users of prescription medication for migraine had received a migraine diagnosis by

Figure 1 Analysis population

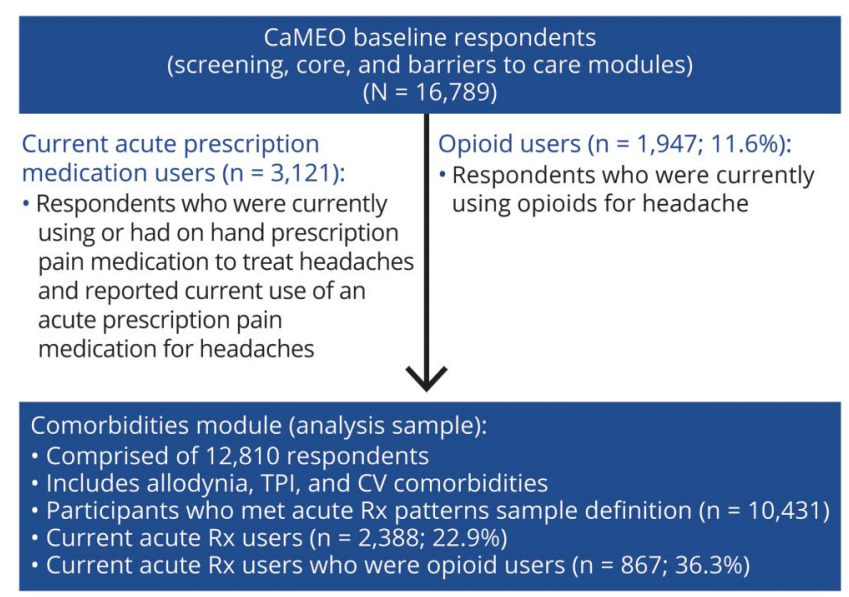

CaMEO = Chronic Migraine Epidemiology and Outcomes; CV = cardiovascular; Rx = prescription; TPI = Total Pain Index. a health care professional (HCP). Opioid users were less likely to have received a migraine diagnosis by an HCP and had more visits to an ED or UC facility. A similar percentage of opioid users (14.4\%) and nonusers (14.9\%) reported that a specialist was treating or managing their headaches. The respondents who reported opioid use were more likely to have their headaches managed by pain specialists, whereas those not reporting opioid use were more likely to have their headaches managed by neurologists or headache specialists (figure 2A). Among the 867 respondents categorized as current opioid users, $213(24.5 \%)$ reported using an opioid on 10 or more days per month. In addition, current opioid users were less likely than opioid nonusers to take triptan or barbiturate medications (figure 2B).

\section{Additional characteristics}

Compared with opioid nonusers, current opioid users had a higher prevalence of allodynia ( $65.6 \%$ vs $57.1 \%)$, diabetes diagnosed by an HCP ( $14.9 \%$ vs $8.1 \%)$, moderate to severe depression based on a PHQ-9 score of at least 10 (49.9\% vs $29.2 \%)$, anxiety based on a GAD-7 score of at least 10 (42.3\% vs $25.6 \%$ ), higher mean TPI scores (18.7 vs 13.7 ), and higher mean TPI scores excluding head, face, and neck ( 8.3 vs 6.7 ) $(p<0.001$ for all). The mean MSSS was lower among opioid users $(16.6$ vs $17.3 ; p<0.001)$. However, a higher proportion of current opioid users than nonusers $(p<0.05)$ reported all CV comorbidities, including heart disease or angina, heart attack or myocardial infarction, irregular heart rhythms, any heart valve issues, hypertension, stroke, and TIA (table 3).

\section{Migraine-related disability and health-related quality of life scores}

Current opioid users and nonusers differed with respect to patient-reported outcomes. Current opioid users had greater headache-related disability based on their MIDAS scores than opioid nonusers. A greater proportion of current opioid users had MIDAS grade IV (figure 3A). Mean MSQ scores were also significantly lower among current opioid users than in opioid nonusers across all 3 of the MSQ domains (figure 3B), indicating that opioid users had reduced migraine-specific quality of life.

\section{Factors associated with opioid use based on multivariable binary logistic regression models}

We ran a series of 5 nested models. Factors significantly associated with opioid use in the fully adjusted model (model 5) included male sex $(p<0.001)$, increasing BMI $(p=0.011)$, presence of allodynia $(p=0.001)$, increasing monthly headache frequency $(10-14$ days vs $0-4$ days: $p=0.034 ; \geq 15$ days vs $0-4$ days: $p=0.001)$, TPI excluding head, face, and neck $(p<$ $0.001)$, anxiety $(p=0.008)$, depression $(p=0.001)$, at least 1 $\mathrm{CV}$ comorbidity $(p<0.001)$, and $\mathrm{ED} / \mathrm{UC}$ facility use for headache in the past 6 months $(p<0.001)$ (table 4$)$. Physiciandiagnosed migraine or chronic migraine $(p<0.001)$ and elevated MSSS $(p<0.001)$ were associated with a significantly decreased likelihood of opioid use. 
Table 1 Demographics of study sample by opioid users and nonusers among persons with migraine using a prescription treatment for migraine

\begin{tabular}{|c|c|c|c|c|c|}
\hline Characteristic & Opioid users $(n=867)$ & Opioid nonusers $(n=1,521)$ & Total $(n=2,388)^{a}$ & $\chi^{2}$ & $p$ Value \\
\hline Age, y & $46.1 \pm 13.7$ & $46.4 \pm 13.3$ & $46.3 \pm 13.5$ & $0.51^{\mathrm{b}}$ & 0.609 \\
\hline Sex & - & - & - & 40.36 & $<0.001$ \\
\hline Men & $230(26.5)$ & $240(15.8)$ & $470(19.7)$ & - & - \\
\hline Women & $637(73.5)$ & $1,281(84.2)$ & $1,918(80.3)$ & - & - \\
\hline White & $737(85.2)$ & $1,328(87.4)$ & $2,065(86.6)$ & 2.35 & 0.125 \\
\hline Married & 459 (52.9) & $855(56.3)$ & $1,314(55.0)$ & 2.44 & 0.118 \\
\hline Employed & $476(54.9)$ & $966(63.5)$ & $1,442(60.4)$ & 17.11 & $<0.001$ \\
\hline Health insurance & $792(91.8)$ & $1,409(93.4)$ & $2,201(92.8)$ & 2.10 & 0.147 \\
\hline Education, $\geq 4$-year degree & $367(42.3)$ & $780(51.3)$ & $1,147(48.0)$ & 17.73 & $<0.001$ \\
\hline BMI, kg/m² & $30.9 \pm 8.4$ & $28.8 \pm 7.4$ & $29.6 \pm 7.8$ & $6.14^{\mathrm{b}}$ & $<0.001$ \\
\hline Income $^{c}$ & - & - & - & 36.22 & $<0.001$ \\
\hline$<\$ 30,000$ & $213(24.7)$ & $239(15.8)$ & $452(19.1)$ & - & - \\
\hline$\$ 30,000-\$ 49,999$ & $138(16.0)$ & $268(17.7)$ & $406(17.1)$ & - & - \\
\hline$\$ 50,000-\$ 74,999$ & $207(24.0)$ & $332(22.0)$ & $539(22.7)$ & - & - \\
\hline$\geq \$ 75,000$ & $303(35.2)$ & $671(44.4)$ & $974(41.1)$ & - & - \\
\hline
\end{tabular}

Abbreviation: $\mathrm{BMI}=$ body mass index.

Values are mean \pm SD or $\mathrm{n}(\%)$.

a Unless otherwise shown or indicated.

${ }^{\mathrm{b}}$ Independent samples $t$ test.

${ }^{\mathrm{c}} \mathrm{n}$ for this category $=2,371$.

In initial models (table 4), full- or part-time employment status and income greater than $\$ 75,000$ /year were associated with higher odds of opioid use, but adjustment for respondents' headache characteristics eliminated these associations. Moderate to severe MIDAS-based disability was associated with opioid use when the model was adjusted for

Table 2 Headache characteristics and use of specialists by opioid users and nonusers

\begin{tabular}{|c|c|c|c|c|c|}
\hline Characteristic & Opioid users $(n=867)$ & Opioid nonusers $(n=1,521)$ & Total $(n=2,388)$ & $\chi^{2}$ & $p$ Value \\
\hline Monthly headache days & $8.3 \pm 7.7$ & $6.5 \pm 6.5$ & $7.2 \pm 7.0^{\mathrm{a}}$ & 6.04 & $<0.001$ \\
\hline Monthly headache days & - & - & - & 36.14 & $<0.001$ \\
\hline $0-4$ & $377(43.5)$ & $815(53.6)$ & $1,192(49.9)$ & - & - \\
\hline $5-9$ & $197(22.7)$ & $352(23.1)$ & $549(23.0)$ & - & - \\
\hline $10-14$ & $124(14.3)$ & $170(11.2)$ & $294(12.3)$ & - & - \\
\hline$\geq 15$ & 169 (19.5) & $184(12.1)$ & $353(14.8)$ & - & - \\
\hline Use of NSAIDs $\geq 15$ days/mo; others $\geq 10$ days $/ \mathrm{mo}$ & $336(38.8)$ & $350(23.0)$ & $686(28.7)$ & 66.85 & $<0.001$ \\
\hline Opioid use $\geq 10$ days $/ \mathrm{mo}$ & $213(24.5)$ & - & - & - & - \\
\hline $\begin{array}{l}\text { Headaches managed by neurology, pain, or } \\
\text { headache specialist, past } 6 \text { months }\end{array}$ & $125(14.4)$ & $226(14.9)$ & $351(14.7)$ & 0.086 & 0.770 \\
\hline Migraine or CM diagnosed by HCP & $584(67.4)$ & $1,311(86.2)$ & $1,895(79.4)$ & 119.58 & $<0.001$ \\
\hline ED/UC, past 6 months & $143(16.5)$ & $124(8.2)$ & $267(11.2)$ & 38.69 & $<0.001$ \\
\hline
\end{tabular}

Abbreviations: $\mathrm{CM}=$ chronic migraine; $\mathrm{ED}=$ emergency department; $\mathrm{HCP}=$ health care professional; $\mathrm{NSAID}=$ nonsteroidal anti-inflammatory drug; $\mathrm{UC}=$ urgent care.

Values are mean \pm SD or $\mathrm{n}(\%)$.

a Independent samples $t$ test. 

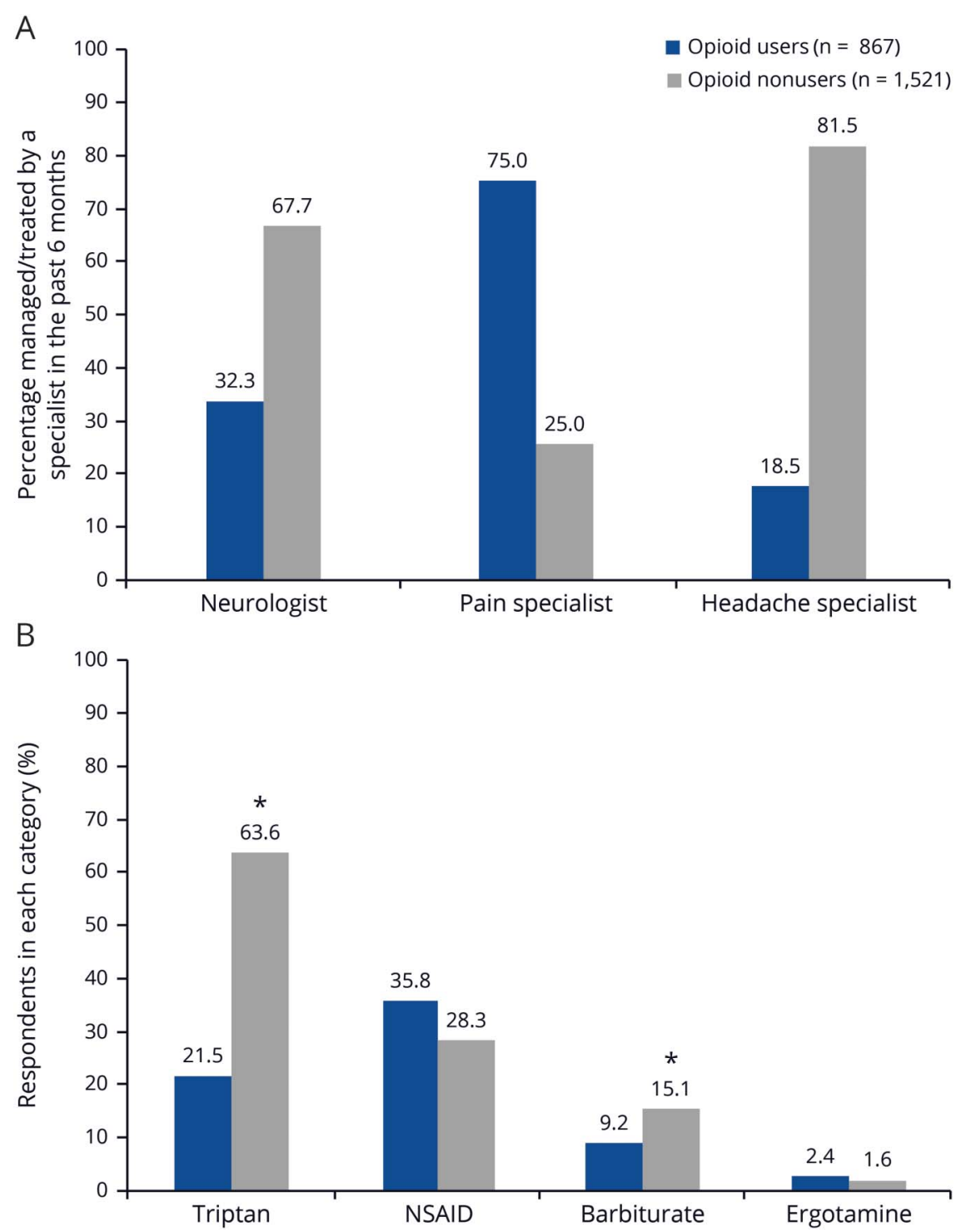

(A) Opioid use and nonuse distribution across specialties differed significantly $\left(X^{2}=29.18 ; p<\right.$ 0.001 ); more opioid users than nonusers reported having their headaches managed by pain specialists. Neurologists and headache specialists managed more opioid nonusers. (B) Medication use among opioid users vs nonusers. This analysis presents medication use meeting criteria of $\geq 15$ days/month for respondents using nonsteroidal anti-inflammatory drugs and $\geq 10$ days/month for all other classes/agents. ${ }^{*} p<$ 0.001 ; other differences not statistically significant. NSAID = nonsteroidal anti-inflammatory drug.

headache characteristics and remained associated when the model was adjusted for psychiatric comorbidities. This association did not persist when past 6-month ED/UC use was added to the model, suggesting that disability is associated with ED/UC use.

\section{Discussion}

Consensus statements and guidelines do not recommend opioids to manage migraine because of limited efficacy, lack of migraine specificity, increased disability, risks of overuse and migraine chronification over the longer term, as well as the potential for dependence, abuse, and misuse, a serious public health concern. ${ }^{7,15,17,25,26}$ Nevertheless, these medications are commonly prescribed to individuals with migraine. 9 The current analysis confirmed that opioid use among individuals with migraine is not uncommon. Results of this study are important for a global audience, especially in countries where prescriptions for opioids are increasing.

The association between male sex and greater opioid use in this analysis is consistent with previous findings from the AMPP study showing that the use of opioids was associated with a greater risk of migraine chronification in men (adjusted OR $[95 \%$ CI $] 2.76[1.20-6.38])$ than in women (1.28 $[0.81-1.97]) .^{27}$ The nature of the relationships among male sex, opioid use, and migraine chronification remains to be unraveled. A recent analysis of acute medication overuse from the Migraine in America Symptoms and Treatment study showed that, in respondents with migraine, men had higher rates of acute medication overuse than did women. ${ }^{26}$ It is unknown whether these findings are a consequence of prescribing patterns, migraine characteristics such as severity or frequency, differing genetic vulnerabilities, or interactions among these or other variables. 
Table 3 Cardiovascular comorbidities of study sample by opioid users and nonusers

\begin{tabular}{|c|c|c|c|c|c|}
\hline Self-report of HCP-diagnosed comorbidity & Opioid users $(n=867)$ & Opioid nonusers $(n=1,521)$ & Total $(n=2,388)$ & $\chi^{2}$ & $p$ Value \\
\hline Heart disease/angina & $39(4.5)$ & $26(1.7)$ & $65(2.7)$ & 16.22 & $<0.001$ \\
\hline Heart attack (MI) & $20(2.3)$ & $16(1.1)$ & $36(1.5)$ & 5.86 & 0.016 \\
\hline Irregular heart rhythms & $140(16.1)$ & $157(10.3)$ & $297(12.4)$ & 17.21 & $<0.001$ \\
\hline Any heart valve disease or abnormality & $54(6.2)$ & $65(4.3)$ & $119(5.0)$ & 4.46 & 0.035 \\
\hline Hypertension & $310(35.8)$ & $354(23.3)$ & $664(27.8)$ & 42.86 & $<0.001$ \\
\hline Stroke & $22(2.5)$ & $16(1.1)$ & $38(1.6)$ & 7.78 & 0.005 \\
\hline TIA & $25(2.9)$ & $22(1.4)$ & $47(2.0)$ & 5.91 & 0.015 \\
\hline
\end{tabular}

Abbreviations: $\mathrm{HCP}=$ health care professional; $\mathrm{MI}=$ myocardial infarction.

Values are $n(\%)$.

Higher prevalence of depression and anxiety was also noted among opioid users compared with nonusers in the AMPP study. ${ }^{9}$ Further research is needed to help determine the nature and directionality of the association between depression and anxiety and opioid use. It is possible that opioids contribute to a worsening of depression and anxiety. In addition, these psychiatric comorbidities could contribute to worsening of headache, with a resulting increase in opioid prescribing. These possibilities are not necessarily mutually exclusive.

In the present analysis, seeking treatment for headache in $\mathrm{ED} /$ UC facilities was associated with opioid use and with moderate to severe disability as measured by MIDAS, an unsurprising finding. Although the reasons for high prescribing rates of opioids in this setting have not been investigated systematically, it may be that HCPs in the ED prefer to use opioids as rescue treatment because of perceived rapidity of their efficacy or perceived short-term safety. It is also possible that a proportion of patients presenting to the ED for migraine treatment have already used and not adequately responded to guideline-recommended medications, such as NSAIDs and triptans. Additional education of the ED/UC and pain specialist physician populations about appropriate acute treatments for migraine attacks may be needed to decrease the prescribing rates of opioids in these settings.

Other associations between opioid use and variables evaluated in this analysis may reflect the diagnostic and treatment challenges with migraine. For example, we noted that a physician diagnosis of migraine and an elevated symptom severity score (MSSS) showed a decreased association with opioid use. The association of physician-diagnosed migraine and decreased opioid use in this analysis may reflect greater understanding of the benefit-risk profile and limitations of opioids among clinicians who are able to make a migraine diagnosis. Higher MSSS scores may result in an increased likelihood of a migraine diagnosis and initiation of more specific medications. The increased use of opioids associated with TPI scores and allodynia may indicate attempts to treat multiple pain presentations with a single agent. It is also possible that opioid-induced hyperalgesia ${ }^{28}$ could contribute to the development of extracephalic pain and allodynia via central sensitization, ${ }^{29}$ thereby contributing to the associations among TPI, allodynia, and increased opioid use.

In this analysis, a substantial proportion of current opioid users reported using an opioid on at least 10 days per month, which puts them at risk for $\mathrm{MOH} .{ }^{30}$ These findings highlight the risk of $\mathrm{MOH}$ with opioid use and the need for more effective acute treatments for migraine.

In the current study, there was no association between income, current employment, or education among opioid users or nonusers. In the AMPP study, opioid use was associated with lower rates of marriage and current employment, as well as lower annual household income. ${ }^{9}$ As in the AMPP study, our analysis revealed a higher incidence of $\mathrm{CV}$ comorbidities in opioid users than nonusers. The design of the current analysis did not permit us to determine if $\mathrm{CV}$ comorbidities were related to opioid use or if HCPs were prescribing opioids rather than triptans to patients with $\mathrm{CV}$ comorbidities owing to the absolute and relative contraindications to triptans because of potential CV risks. However, among 29,025 participants of the prospective Reasons for Geographic and Racial Differences in Stroke (REGARDS) study, adult women, but not men, using prescription opioids were at higher risk for coronary heart disease and CV death. ${ }^{31}$

Overall, our results confirm that opioid use for the treatment of migraine is common and are consistent with the results from the AMPP study, which showed that $15.9 \%$ of people with migraine were current opioid users for migraine and $13.8 \%$ were former opioid users for migraine. ${ }^{9}$ However, it is important to note that the samples of the 2 studies differed in that the CaMEO population was younger and had a slightly higher income than the AMPP population ${ }^{32}$; therefore, direct comparisons of percentages cannot be made. In addition, the nature of this current analysis does not allow us to determine causation or directionality, as our data are derived from a cross-sectional 

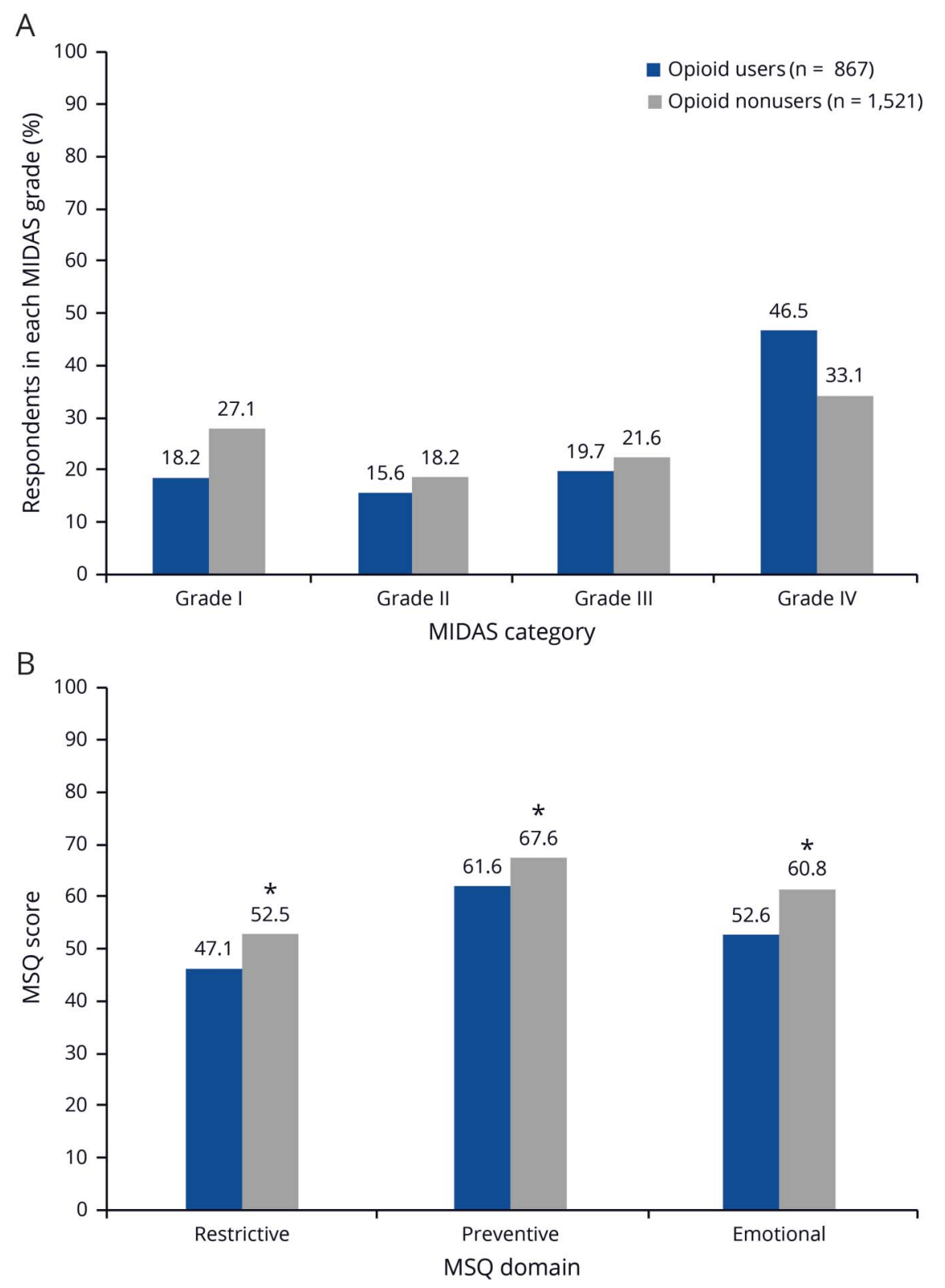

(A) For migraine-related disability among opioid
users and nonusers, current opioid users had
a greater headache-related burden overall than
did opioid nonusers $\left(\chi^{2}=47.55 ; p<0.001\right)$. (B)
Migraine-related quality of life scores among
opioid users and nonusers. ${ }^{*} p<0.001$ for all
between-group comparisons. MIDAS = Migraine
Disability Assessment; MSQ = Migraine-Specific
Quality of Life Questionnaire.

analysis. Nevertheless, the results provide descriptive information about the characteristics of opioid users and nonusers. Further examination of our data may help to characterize the types of patients who are not well-served by currently available acute treatments for migraine attacks and spur research into causative factors and potential solutions, such as new treatments. Continuing this line of inquiry also may lead to a better understanding of the patterns of care accessed by those with migraine and thereby reveal potential gaps in HCP understanding of optimal migraine treatment. Finally, it is hoped that better definition of these issues will lead to a reduction in the use of opioids for the acute treatment of migraine attacks. Within this context, identifying modifiable variables (such as obesity, some comorbidities, medication overuse, and lifestyle factors) and unmodifiable variables (such as age, sex, race, and genetic factors) in migraine and its management may help to close the gaps to optimal management.

The limitations of the CaMEO study have been discussed previously. ${ }^{19}$ The CaMEO study design used probability sampling from a nationally distributed online panel to provide a broad, representative US population; nevertheless, participation rates were low, and this subanalysis comprised a small group of those individuals using prescription medication to treat headache, which may have introduced participation bias. However, the analysis sample was limited to respondents who were consistent in their reporting of medication use, supporting the reliability of study findings. Our assessment did not include information on the number of doses per day and, therefore, cannot be used to evaluate any dose-response 


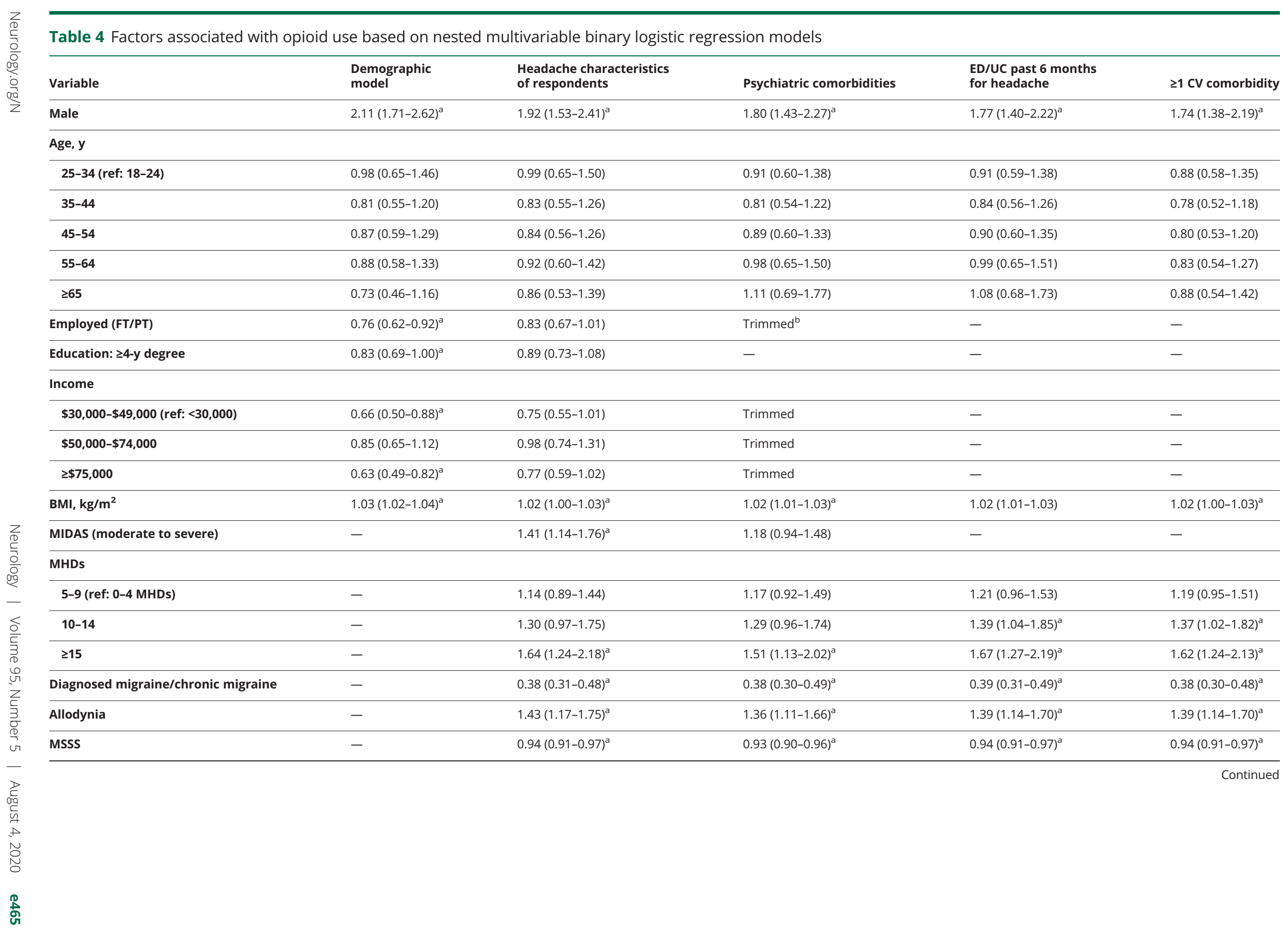


relationship with outcome variables. It is likely that opioid users represent a diverse population with potentially varied outcomes. Currently, available data cannot distinguish between those who are receiving opioids in the ED/UC setting for migraine and those visiting these facilities more frequently for other comorbidities. Data are self-reported and were not confirmed by HCPs or medical records. Strengths of the CaMEO study include that it is a large nationwide sample ( $\mathrm{n}=$ 16,789 ) that provides a substantial volume of data to assist in characterizing people with migraine in terms of comorbidities, treatment consultation, diagnosis, and patterns of care. Furthermore, descriptive data such as those provided are limited in the literature, as many published studies have been limited to the assessment of sociodemographic factors associated with opioid misuse, abuse, and overdose. ${ }^{33-35}$

The current analysis of population (as opposed to clinical) data extends our knowledge about the associations among sociodemographic, headache, and other characteristics associated with opioid use in those with migraine. Opioid use is generally associated with greater headache-related burden; markers of worse health, including elevated BMI and CV, and psychiatric comorbidities; elevated TPI and ED/UC facility use; and poorer quality of life. Variables associated with a higher likelihood of opioid use include absence of a physician diagnosis of migraine and more monthly headache days. The results reported here may help HCPs to identify individuals at risk for opioid use, and future research may help to elucidate the nature of associations between identified variables and opioid use, including their directionality.

\section{Acknowledgment}

Writing and editorial assistance was provided to the authors by Peloton Advantage, LLC, an OPEN Health company, Parsippany, NJ, and was funded by Allergan plc. The opinions expressed in this article are those of the authors. The authors received no honorarium/fee or other form of financial support related to the development of this article. Valerie Marske of Vedanta Research worked with authors to develop the assessment tools and to manage respondent recruiting and data collection.

\section{Study funding}

This study was sponsored by Allergan plc, Dublin, Ireland.

\section{Disclosure}

R.B. Lipton is the Edwin S. Lowe Professor of Neurology at the Albert Einstein College of Medicine in New York. He receives research support from the NIH: 2PO1 AG003949 (mPI), 5U10 NS077308 (PI), RO1 NS082432 (investigator), 1RF1 AG057531 (site PI), RF1 AG054548 (investigator), 1RO1 AG048642 (investigator), R56 AG057548 (investigator), K23 NS09610 (mentor), K23AG049466 (mentor), and K23 NS107643 (mentor). He also receives support from the Migraine Research Foundation and the National Headache Foundation. He serves on the editorial board of Neurology ${ }^{\circledR}$ and is senior advisor to Headache and associate editor for 
Cephalalgia. He has reviewed for the NIA and NINDS; holds stock options in eNeura Therapeutics and Biohaven Holdings; serves as consultant, advisory board member, or has received honoraria from American Academy of Neurology, Alder, Allergan, American Headache Society, Amgen, Autonomic Technologies, Avanir, Biohaven, Biovision, Boston Scientific, Dr. Reddy's, Electrocore, Eli Lilly, eNeura Therapeutics, GlaxoSmithKline, Merck, Pernix, Pfizer, Teva, Trigemina, Vector, and Vedanta. He receives royalties from Wolff's Headache, 7th and 8th edition (Oxford Press University, 2009), Wiley, and Informa. D.C. Buse has received grant support and honoraria from Allergan, Avanir, Amgen, Biohaven, Eli Lilly and Company, and Promius and for work on the editorial board of Current Pain and Headache Reports. She was not compensated for writing or presenting any abstracts, posters, platforms, manuscripts, editorials, or other scientific communications. B.W. Friedman reports no disclosures relevant to the manuscript. L. Feder is an employee of Peloton Advantage, LLC, an OPEN Health company. A. Manack Adams is an employee of Allergan plc. K.M. Fanning is an employee of Vedanta Research, which has received research funding from Allergan, Amgen, Dr. Reddy's Laboratories, Eli Lilly, GlaxoSmithKline, Merck \& Co., Inc., and Novartis, via grants to the National Headache Foundation. Vedanta has received funding directly from Allergan for work on the CaMEO study. M.L. Reed is Managing Director of Vedanta Research, which has received research funding from Allergan, Amgen, Eli Lilly, GlaxoSmithKline, Merck \& Co., Inc., and Promius, and grants from the National Headache Foundation. Vedanta Research has received funding directly from Allergan for work on the CaMEO study. T.J. Schwedt has served as a consultant for Alder, Allergan, Amgen, ATI, Aural Analytics, Avanir, Cipla, Dr. Reddy's Laboratories, Eli Lilly, Ipsen Bioscience, Nocira, Novartis, Promius Pharma, Second Opinion, Teva, and Xoc. He holds stock options in Aural Analytics, Nocira, and Second Opinion and has received research funding from Amgen. Go to Neurology.org/ $\mathrm{N}$ for full disclosures.

\section{Publication history}

Received by Neurology May 20, 2019. Accepted in final form November 7, 2019.

Appendix Authors

\begin{tabular}{lll}
\hline Name & Location & Contribution \\
\hline $\begin{array}{l}\text { Richard B. } \\
\text { Lipton, MD }\end{array}$ & $\begin{array}{l}\text { Albert Einstein } \\
\text { College of Medicine, } \\
\text { Bronx, NY }\end{array}$ & $\begin{array}{l}\text { Designed and conceptualized } \\
\text { study, major role in the acquisition } \\
\text { of data, interpreted the data, } \\
\text { contributed to data analysis, } \\
\text { drafted the manuscript for } \\
\text { intellectual content, revised the } \\
\text { manuscript for intellectual content }\end{array}$ \\
\hline Dawn C. & $\begin{array}{l}\text { Albert Einstein } \\
\text { Buse, PhD }\end{array}$ & $\begin{array}{l}\text { Designed and conceptualized } \\
\text { study, major role in the } \\
\text { acquisition of data, interpreted } \\
\text { the data, drafted the manuscript } \\
\text { for intellectual content, revised } \\
\text { the manuscript for intellectual } \\
\text { content }\end{array}$
\end{tabular}

Appendix (continued)

\begin{tabular}{lll}
\hline Name & Location & Contribution \\
\hline $\begin{array}{l}\text { Benjamin W. } \\
\text { Mriedman, }\end{array}$ & $\begin{array}{l}\text { Albert Einstein } \\
\text { College of Medicine, } \\
\text { Bronx, NY }\end{array}$ & $\begin{array}{l}\text { Interpreted the data, drafted the } \\
\text { manuscript for intellectual } \\
\text { content, revised the manuscript } \\
\text { for intellectual content }\end{array}$ \\
$\begin{array}{lll}\text { Lisa Feder, } \\
\text { PhD }\end{array}$ & $\begin{array}{l}\text { Peloton Advantage, } \\
\text { LLC, Parsippany, NJ }\end{array}$ & $\begin{array}{l}\text { Drafted the manuscriptand } \\
\text { revised the manuscript under the } \\
\text { guidance of the authors and } \\
\text { approved the final manuscript for } \\
\text { submission }\end{array}$ \\
\hline $\begin{array}{l}\text { Aubrey } \\
\text { Manack }\end{array}$ & $\begin{array}{l}\text { Allergan plc, Irvine, } \\
\text { CAams, PhD }\end{array}$ & $\begin{array}{l}\text { Designed and conceptualized } \\
\text { study, major role in the } \\
\text { acquisition of data, interpreted } \\
\text { the data, drafted the manuscript } \\
\text { for intellectual content, revised } \\
\text { the manuscript for intellectual } \\
\text { content }\end{array}$ \\
\hline
\end{tabular}

\begin{tabular}{lll}
\hline $\begin{array}{l}\text { Kristina M. } \\
\text { Fanning, } \\
\text { PhD }\end{array}$ & $\begin{array}{l}\text { Vedanta Research, } \\
\text { Chapel Hill, NC }\end{array}$ & $\begin{array}{l}\text { Interpreted the data, drafted the } \\
\text { manuscript for intellectual } \\
\text { content, revised the manuscript } \\
\text { for intellectual content }\end{array}$ \\
\hline $\begin{array}{l}\text { Michael L. } \\
\text { Reed, PhD }\end{array}$ & $\begin{array}{l}\text { Vedanta Research, } \\
\text { Chapel Hill, NC }\end{array}$ & $\begin{array}{l}\text { Designed and conceptualized } \\
\text { study, major role in the } \\
\text { enrollment of patients and the } \\
\text { acquisition of data, interpreted } \\
\text { the data, drafted the manuscript } \\
\text { for intellectual content, revised } \\
\text { the manuscript for intellectual } \\
\text { content }\end{array}$ \\
& &
\end{tabular}

\begin{tabular}{lll}
\hline Todd J. & Mayo Clinic, & Interpreted the data, drafted the \\
Schwedt, & Phoenix, AZ & manuscript for intellectual \\
MD & & $\begin{array}{l}\text { content, revised the manuscript } \\
\text { for intellectual content }\end{array}$
\end{tabular}

\section{References}

1. Headache Classification Committee of the International Headache Society. The International Classification of Headache Disorders, 3rd edition. Cephalalgia 2018;38:1-211.

2. Pietrobon D, Moskowitz MA. Pathophysiology of migraine. Annu Rev Physiol 2013; 75:365-391.

3. GBD 2016 Disease and Injury Incidence and Prevalence Collaborators. Global, regional, and national incidence, prevalence, and years lived with disability for 328 diseases and injuries for 195 countries, 1990-2016: a systematic analysis for the Global Burden of Disease Study 2016. Lancet 2017;390:1211-1259.

4. Lipton RB, Bigal ME, Diamond M, Freitag F, Reed ML, Stewart WF. Migraine prevalence, disease burden, and the need for preventive therapy. Neurology 2007;68: 343-349.

5. Lipton RB, Bigal ME, Scher AI, Stewart WF. The global burden of migraine. J Headache Pain 2003;4:S3-S11.

6. Buse DC, Murray S, Dumas PK, et al. Life with migraine, effect on relationships, career and finances, and overall health and well-being results of the Chronic Migraine Epidemiology and Outcomes (CAMEO) study [abstract MTIS2008-009]. Cephalalgia 2018;38(1 suppl):9-10.

7. Silberstein SD. Practice parameter: evidence-based guidelines for migraine headache (an evidence-based review): report of the Quality Standards Subcommittee of the American Academy of Neurology. Neurology 2000;55:754-762.

8. Bonafede M, Wilson K, Xue F. Long-term treatment patterns of prophylactic and acute migraine medications and incidence of opioid-related adverse events in patients with migraine. Cephalalgia 2019;39:1086-1098.

9. Buse DC, Pearlman SH, Reed ML, Serrano D, Ng-Mak DS, Lipton RB. Opioid use and dependence among persons with migraine: results of the AMPP study. Headache 2012;52:18-36.

10. Friedman BW, West J, Vinson DR, Minen MT, Restivo A, Gallagher EJ. Current management of migraine in US emergency departments: an analysis of the National Hospital Ambulatory Medical Care Survey. Cephalalgia 2015;35:301-309.

11. Franklin GM. Opioids for chronic noncancer pain: a position paper of the American Academy of Neurology. Neurology 2014;83:1277-1284.

12. Langer-Gould AM, Anderson WE, Armstrong MJ, et al. The American Academy of Neurology's top five choosing wisely recommendations. Neurology 2013;81:1004-1011.

13. Lipton RB, Fanning KM, Serrano D, Reed ML, Cady R, Buse DC. Ineffective acute treatment of episodic migraine is associated with new-onset chronic migraine. Neurology 2015;84:688-695. 
14. Mathew NT, Reuveni U, Perez F. Transformed or evolutive migraine. Headache 1987;27:102-106.

15. Bigal ME, Lipton RB. Excessive acute migraine medication use and migraine progression. Neurology 2008;71:1821-1828.

16. Bigal ME, Lipton RB. Clinical course in migraine: conceptualizing migraine transformation. Neurology 2008;71:848-855.

17. Bigal ME, Lipton RB. Overuse of acute migraine medications and migraine chronification. Curr Pain Headache Rep 2009;13:301-307.

18. Finocchi C, Viani E. Opioids can be useful in the treatment of headache. Neurol Sci 2013;34(suppl 1):S119-S124.

19. Manack Adams A, Serrano D, Buse DC, et al. The impact of chronic migraine: the Chronic Migraine Epidemiology and Outcomes (CaMEO) study methods and baseline results. Cephalalgia 2015;35:563-578.

20. Lipton RB, Stewart WF, Diamond S, Diamond ML, Reed M. Prevalence and burden of migraine in the United States: data from the American Migraine Study II. Headache 2001;41:646-657.

21. Stewart WF, Lipton RB, Dowson AJ, Sawyer J. Development and testing of the Migraine Disability Assessment (MIDAS) Questionnaire to assess headache-related disability. Neurology 2001;56:S20-S28.

22. Lipton RB, Bigal ME, Ashina S, et al. Cutaneous allodynia in the migraine population. Ann Neurol 2008;63:148-158.

23. Kroenke K, Spitzer RL, Williams JB. The PHQ-9: validity of a brief depression severity measure. J Gen Intern Med 2001;16:606-613.

24. Spitzer RL, Kroenke K, Williams JB, Lowe B. A brief measure for assessing generalized anxiety disorder: the GAD-7. Arch Intern Med 2006;166:1092-1097.

25. Matchar DB, Young WB, Rosenberg JH, et al. Evidence-Based Guidelines for Migraine Headache in the Primary Care Setting: Pharmacological Management of Acute Attacks. Minneapolis: American Academy of Neurology; 2000.
26. Schwedt TJ, Alam A, Reed ML, et al. Factors associated with acute medication overuse in people with migraine: results from the 2017 Migraine in America Symptoms and Treatment (MAST) study. J Headache Pain 2018;19:38.

27. Bigal ME, Serrano D, Buse D, Scher A, Stewart WF, Lipton RB. Acute migraine medications and evolution from episodic to chronic migraine: a longitudinal population-based study. Headache 2008;48:1157-1168.

28. Roeckel LA, Le Coz GM, Gaveriaux-Ruff C, Simonin F. Opioid-induced hyperalgesia: cellular and molecular mechanisms. Neuroscience 2016;338:160-182.

29. Burstein R, Noseda R, Borsook D. Migraine: multiple processes, complex pathophysiology. J Neurosci 2015;35:6619-6629.

30. Thorlund K, Sun-Edelstein C, Druyts E, et al. Risk of medication overuse headache across classes of treatments for acute migraine. J Headache Pain 2016;17:107.

31. Khodneva Y, Muntner P, Kertesz S, Kissela B, Safford MM. Prescription opioid use and risk of coronary heart disease, stroke, and cardiovascular death among adults from a prospective cohort (REGARDS study). Pain Med 2016;17:444-455.

32. Lipton RB, Manack Adams A, Buse DC, Fanning KM, Reed ML. A comparison of the Chronic Migraine Epidemiology and Outcomes (CaMEO) study and American Migraine Prevalence and Prevention (AMPP) study: demographics and headacherelated disability. Headache 2016;56:1280-1289.

33. Chang YP. Factors associated with prescription opioid misuse in adults aged 50 or older. Nurs Outlook 2018;66:112-120.

34. Zocca J, Sharifzadeh Y, Mackey S, Hah J. Factors associated with prescription opioid abuse in a cross-sectional cohort of new pain clinic patients [abstract 149]. J Pain 2015; 16:S13.

35. Nechuta SJ, Tyndall BD, Mukhopadhyay S, McPheeters ML. Sociodemographic factors, prescription history and opioid overdose deaths: a statewide analysis using linked PDMP and mortality data. Drug Alcohol Depend 2018;190: $62-71$. 


\section{Neurology}

\section{Characterizing opioid use in a US population with migraine: Results from the CaMEO study}

Richard B. Lipton, Dawn C. Buse, Benjamin W. Friedman, et al.

Neurology 2020;95;e457-e468 Published Online before print June 11, 2020

DOI 10.1212/WNL.0000000000009324

This information is current as of June 11, 2020

\section{Updated Information \&} Services

References

Citations

Subspecialty Collections

Permissions \& Licensing

Reprints including high resolution figures, can be found at: http://n.neurology.org/content/95/5/e457.full

This article cites 34 articles, 8 of which you can access for free at: http://n.neurology.org/content/95/5/e457.full\#ref-list-1

This article has been cited by 6 HighWire-hosted articles: http://n.neurology.org/content/95/5/e457.full\#\#otherarticles

This article, along with others on similar topics, appears in the following collection(s):

All Health Services Research

http://n.neurology.org/cgi/collection/all_health_services_research

Burden of disease

http://n.neurology.org/cgi/collection/burden_of_disease

Migraine

http://n.neurology.org/cgi/collection/migraine

Risk factors in epidemiology

http://n.neurology.org/cgi/collection/risk_factors_in_epidemiology

Information about reproducing this article in parts (figures,tables) or in its entirety can be found online at:

http://www.neurology.org/about/about_the_journal\#permissions

Information about ordering reprints can be found online:

http://n.neurology.org/subscribers/advertise

Neurology ${ }^{\circledR}$ is the official journal of the American Academy of Neurology. Published continuously since 1951, it is now a weekly with 48 issues per year. Copyright Copyright ( 2020 The Author(s). Published by Wolters Kluwer Health, Inc. on behalf of the American Academy of Neurology.. All rights reserved. Print ISSN: 0028-3878. Online ISSN: 1526-632X.

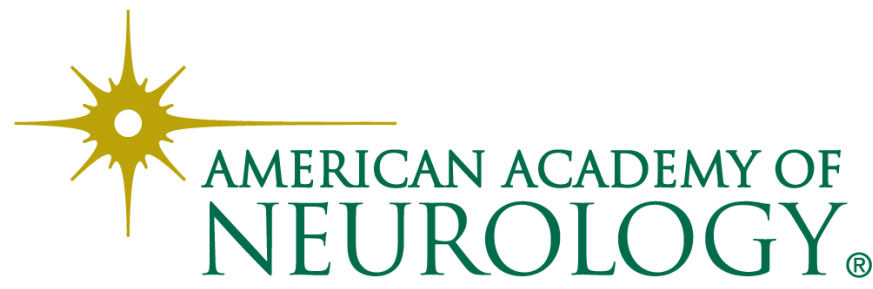

